\title{
07AP0 I - 2 Nonintubated Thoracoscopic Surgery for Lung Tumors in Patients with Compromised Lung Function
}

Man-Ling Wang, MD', Ming-Hui Hung, MD, MS ${ }^{1,2}$, Hsao-Hsun Hsu, MD, $\mathrm{PhD}^{3}$, Kuang-
Cheng Chan, MD ${ }^{1}$, Ya-Jung Cheng, MD, $\mathrm{PhD}^{1}$ and Jin-Shing Chen, MD, $\mathrm{PhD}^{3,4}$

${ }^{1}$ Department of Anesthesiology, ${ }^{2}$ Graduate Institute of Clinical Medicine, ${ }^{3}$ Division of Thoracic Surgery, Department of Surgery, ${ }^{4}$ Department of Traumatology, National Taiwan University Hospital and National Taiwan University College of Medicine, Taipei, Taiwan

\section{Background}

Patients with compromised lung function or chronic obstructive pulmonary disease are considered high-risk for intubated general anesthesia, which may preclude them from surgical treatment for lung tumors. We evaluated the feasibility and safety of nonintubated video-assisted thoracoscopic surgery (VATS) for the surgical management of lung tumors in patients with compromised lung function.

\section{Material and Method}

From August 2009 to December 2014, 28 patients with compromised lung function (preoperative forced expiratory volume in 1 second, $\mathrm{FEV}_{1}<70 \%$ of predicted) underwent nonintubated VATS for managing lung tumors using a combination of thoracic epidural anesthesia or intercostal nerve block and intrathoracic vagal block with target-controlled sedation.

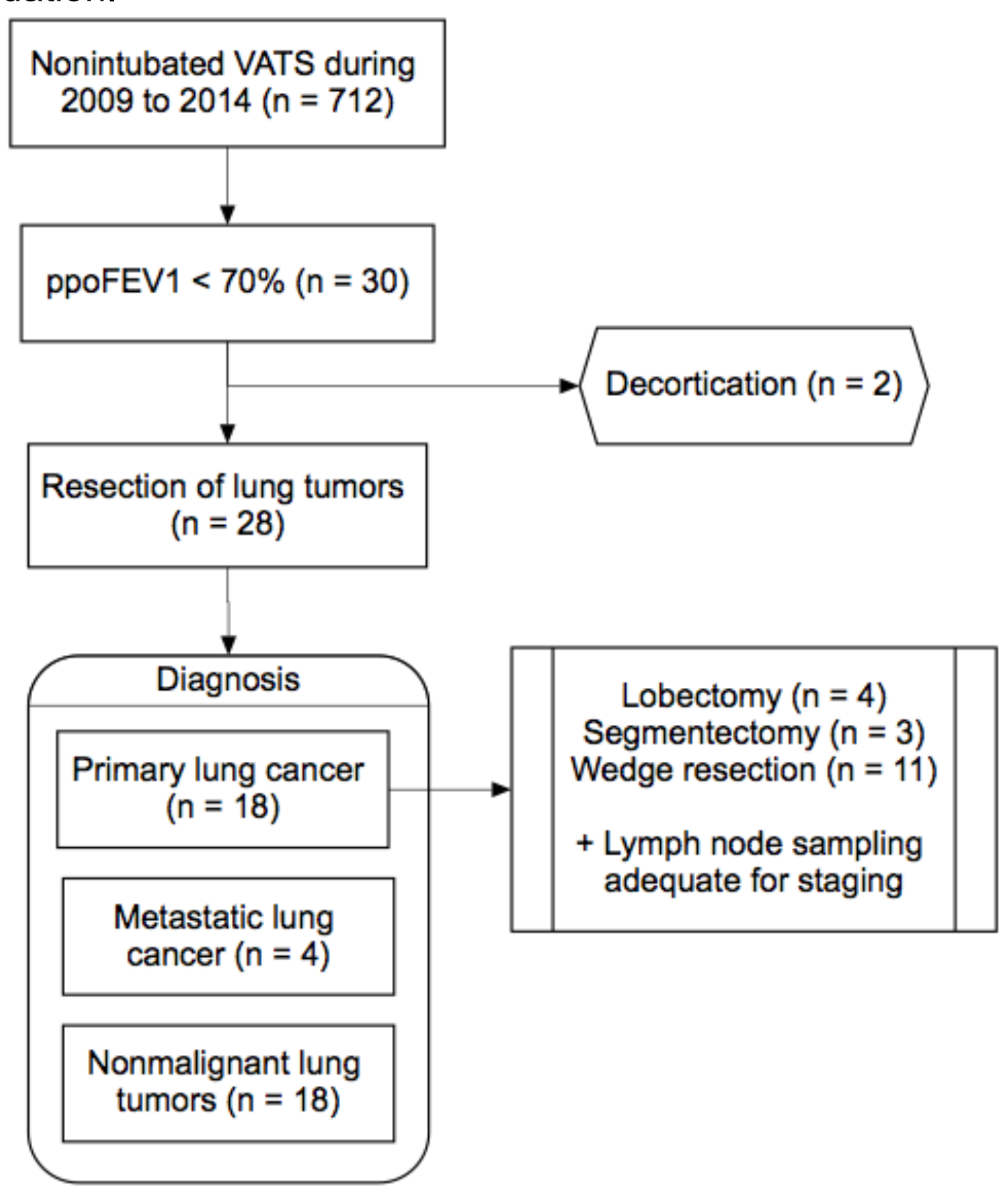

\section{Results}

One patient $(4 \%)$ required conversion to intubated one-lung ventilation because of persistent wheezing and labored breathing. Two patients (7\%) developed acute exacerbations of chronic obstructive pulmonary disease, and atrial fibrillation occurred in 1 patient (4\%).

This work was supported in part by research grants from National Taiwan University Hospital (NTUH104-P08) and the Taiwan Lung Foundation, Taipei, Taiwan.
Five patients $(18 \%)$ developed air leakage more than 5 days postoperatively while subcutaneous emphysema in 6 patients. The median durations of postoperative chest tube drainage was 3 days while the median hospital stay was 6 days.

\begin{tabular}{|c|c|}
\hline Characteristic & Value $(n=28)$ \\
\hline Age, yrs & $68.8 \pm 12.8$ \\
\hline Sex (male) & $19(68 \%)$ \\
\hline Height, cm & $161.9 \pm 8.6$ \\
\hline Weight, kg & $57.9 \pm 9.0$ \\
\hline Body Mass Index (BMI) & $22.0 \pm 2.3$ \\
\hline History of smoking, $\mathrm{n}(\%)$ & $20(71 \%)$ \\
\hline \multicolumn{2}{|c|}{ Preoperative lung function, $\%$ of predicted } \\
\hline FVC (\% of predicted) & $76.7 \pm 13.8$ \\
\hline $\mathrm{FEV}_{1}(\%$ of predicted $)$ & $57.9 \pm 13.1$ \\
\hline $\mathrm{FEV}_{1} / \mathrm{FVC}(\%)$ & $59.4 \pm 15.4$ \\
\hline Tumor size (mm) & $24.4 \pm 16.7$ \\
\hline \multicolumn{2}{|l|}{ Table 2. Anesthetic Results } \\
\hline Variable & Value $(n=28)$ \\
\hline $\begin{array}{l}\text { Anesthetic induction duration, min } \\
\text { Perioperative } \mathrm{PaO}_{2} / \mathrm{FiO}_{2} \text { ratio }\end{array}$ & $20.0 \pm 10.3$ \\
\hline Pre-OLB $(n=17)$ & $428 \pm 108$ \\
\hline Intra-OLB $(n=20)$ & $245 \pm 84$ \\
\hline Post-OLB $(n=19)$ & $388 \pm 99$ \\
\hline \multicolumn{2}{|l|}{ Perioperative $\mathrm{PaCO}_{2}, \mathrm{~mm} \mathrm{Hg}$} \\
\hline Pre-OLB $(n=17)$ & $40.3 \pm 4.9$ \\
\hline Intra-OLB $(n=20)$ & $64.1 \pm 19.4$ \\
\hline Post-OLB $(n=19)$ & $44.5 \pm 9.7$ \\
\hline Lowest $\mathrm{SpO}_{2}$ during operation, $\%$ & $96.3 \pm 4.3$ \\
\hline Blood loss, mL & $51.7 \pm 58.0$ \\
\hline
\end{tabular}

\section{Conclusions}

Nonintubated thoracoscopic surgery is technically feasible and clinically safe for experienced surgeon and anesthesiologist. It may be applied as an alternative to intubated general anesthesia in managing lung tumors in selected patients with compromised lung function. 